\title{
Evaluating the Dental Caries-Related Information on Brazilian Websites: Qualitative Study
}

Patricia Estefania Ayala Aguirre ${ }^{1 *}$, DDS; Melina Martins Coelho ${ }^{1 *}$; Daniela Rios ${ }^{1 *}, \mathrm{PhD}$; Maria Aparecida Andrade Moreira Machado $^{1 *}, \mathrm{PhD}$; Agnes Fátima Pereira Cruvinel ${ }^{2 *}, \mathrm{PhD}$; Thiago Cruvinel ${ }^{1 *}$, DDS, MSc (Oral Surgery), PhD

${ }^{1}$ Department of Pediatric Dentistry, Orthodontics and Public Health, Bauru School of Dentistry, University of São Paulo, Bauru, Brazil

${ }^{2}$ Discipline of Public Health, School of Medicine, Federal University of Fronteira Sul, Chapecó, Brazil

*all authors contributed equally

Corresponding Author:

Thiago Cruvinel, DDS, MSc (Oral Surgery), PhD

Department of Pediatric Dentistry, Orthodontics and Public Health

Bauru School of Dentistry

University of São Paulo

Al. Dr. Octávio Pinheiro Brisolla, 9-75

Vila Universitária

Bauru, 17012-901

Brazil

Phone: 551432455229

Fax: 551432234679

Email: thiagocruvinel@ fob.usp.br

\begin{abstract}
Background: Dental caries is the most common chronic oral disease, affecting 2.4 billion people worldwide who on average have 2.11 decayed, missing, or filled teeth. It impacts the quality of life of patients, socially and economically. However, the comprehension of dental caries may be difficult for most people, as it involves a multifactorial etiology with the interplay between the tooth surface, the dental biofilm, dietary fermentable carbohydrates, and genetic and behavioral factors. Therefore, the production of effective materials addressed to the education and counseling of patients for the prevention of dental caries requires a high level of specialization. In this regard, the dental caries-related contents produced by laypersons and their availability on the Internet may be low-quality information.
\end{abstract}

Objective: The aim of this study was to assess the readability and the quality of dental caries-related information on Brazilian websites.

Methods: A total of 75 websites were selected through Google, Bing, Yahoo!, and Baidu. The websites were organized in rankings according to their order of appearance in each one of the 4 search engines. Furthermore, 2 independent examiners evaluated the quality of websites using the DISCERN questionnaire and the Journal of American Medical Association (JAMA) benchmark criteria. The readability of the websites was assessed by the Flesch Reading Ease adapted to Brazilian Portuguese (FRE-BP). In addition, the information presented on the websites was categorized as etiology, prevention, and treatment of dental caries. The statistical analysis was performed using Spearman rank correlation coefficient, Mann-Whitney U test, hierarchical clustering analysis by Ward minimum variance method, Kruskal-Wallis test, and post hoc Dunn test. $P<.05$ was considered significant.

Results: The Web contents were considered to be of poor quality by DISCERN (mean 33.48, standard deviation, SD 9.06) and JAMA (mean 1.12, SD 0.97) scores, presenting easy reading levels (FRE-BP: mean 62.93, SD 10.15). The rankings of the websites presented by Google $(\rho=-.22, P=.08)$, Baidu $(\rho=-.19, P=.53)$, Yahoo! $(\rho=.22, P=.39)$, and Bing $(\rho=-.36, P=.23)$ were not correlated with DISCERN scores. Moreover, the quality of websites with health- and nonhealth-related authors was similar $(P=.27$ for DISCERN and $P=.47$ for JAMA); however, the pages with a greater variety of dental caries information showed significantly higher quality scores than those with limited contents $(P=.009)$.

Conclusions: On the basis of this sample, dental caries-related contents available on Brazilian websites were considered simple, accessible, and of poor quality, independent of their authorship. These findings indicate the need for the development of specific 
policies focused on the stimulus for the production and publication of Web health information, encouraging dentists to guide their patients in searching for recommended oral health websites.

(J Med Internet Res 2017;19(12):e415) doi: 10.2196/jmir.7681

\section{KEYWORDS}

dental caries; internet; consumer health information; health education

\section{Introduction}

The delivery of health care is in a rapid transition from a paternalistic approach to a person-centered model [1,2]. This process aims to improve health outcomes by the construction of a shared decision-making process between health professionals and patients [3,4], characterized by the greater involvement of people in the resolutions and actions concerning their own health [5-10]. The effectiveness of this novel model, however, may be harmed by a considerable number of barriers, such as low education, inadequate access to knowledge, and social and economic deprivation [11].

Dental caries is the most common chronic oral disease worldwide [12], affecting 2.4 billion people [13,14] who on average have 2.11 decayed, missing, or filled teeth [15]. Untreated dental caries impact the quality of life of individuals, socially and economically [16,17], being the first cause of toothache $(24.3 \%)$ and tooth loss $(86 \%)$ among Brazilian citizens $[18,19]$. In addition, dental caries is the fourth most expensive oral condition to be treated [20]; consequently, people are increasingly interested in dental caries-related Web information, particularly about its symptoms and therapies [21]. This disease involves a complex multifactorial etiology, with the interplay between the tooth surface, the dental biofilm, dietary fermentable carbohydrates, and genetic and behavioral factors, which requires a high level of specialization for the production of effective materials addressed to the education and counseling of patients [22-24]. In this regard, the availability of inaccurate contents in open electronic sources may augment the risk of consumption of low-quality dental caries-related information, hampering the person-professional relationship [25,26] and raising the chance of health damages [27]. Even considering habitual Web health consumers and adequate literates, who are more predisposed to identify and reject poor quality information, their decisions are still based on empirical features, such as the order of appearance of links in the search engines, the design factors, and the complexity and the style of information [28,29].

Several studies have already assessed the quality of Web information related to different health conditions [30-39]; however, there is no evidence about the quality of dental Web contents available in Brazil. The aim of this study was to assess the readability and the quality of dental caries-related information retrieved on Brazilian websites.

\section{Methods}

\section{Study Design}

This study analyzed the quality of dental caries-related information available on Brazilian websites. After the development of a specific search strategy, the websites were retrieved by Google Search, Yahoo!, Bing, and Baidu. Duplicates, nonspecific, inaccessible, and/or scientific links were excluded. The websites were evaluated by 2 independent examiners using the DISCERN questionnaire [40], the Journal of American Medical Association (JAMA) benchmark criteria [41], and the Flesch Reading Ease adapted to Brazilian Portuguese (FRE-BP) [42]. Furthermore, the websites were dichotomized by the nature of their authorship (health- or nonhealth-related authors). Finally, the websites' identities were determined by cluster analysis in accordance with the combination of their respective contents (etiology, prevention, and/or treatment of dental caries).

\section{Search Strategy}

The search strategy was designed with regard to the relevance of terms employed by the Internet users. Initially, a general query was performed on Google Search to confirm the link of Brazilian Portuguese words to dental caries issues. Additional terms automatically generated by the Keyword Planner were included in the analysis. The relevance of each one of 56 terms was subsequently examined in Google Trends by observing the monthly variation of their search volume index between the years 2004 and 2015, including all categories of Web queries performed in Brazil (Multimedia Appendix 1). After excluding 53 keywords with irrelevant volume searches, the final search strategy was constructed by the association of three terms ("cárie"+ "carie"+ "carie dentaria"), which correspond to synonyms and typos of dental caries written in Brazilian Portuguese.

\section{Selection of Websites}

The websites were selected through the 4 search engines with the largest market share: Google Search, Baidu, Yahoo!, and Bing [43]. On March 21, 2016, the searches were performed using a computer connected to the Internet, previously set up by clearing the cookies and history of each browser. Advanced queries were filtered by idiom (Portuguese) and country (Brazil). The retrieved links were ordered in rankings, considering the position of their appearance in each search engine tool.

Subsequently, the websites were accessed and registered using the WebCite [44], an online service that archive the information exactly as it was recovered, avoiding changes and updates for further analysis.

Finally, the websites were dichotomized according to the nature of their authorship in health- and nonhealth-related authors. Websites or blogs developed by dental or medical associations, universities, educational institutions, health companies, or health professionals were classified as health-related authors. All other pages were classified as nonhealth-related authors. Furthermore, the information presented on the websites was categorized as 
etiology, prevention, and/or treatment of dental caries. The presence or absence of these contents was graphically represented by the software Genesis (version 1.7.7, Graz, Austria), characterizing the identity of each website $[45,46]$.

\section{The Assessment of Quality of Websites}

Two independent examiners (PEAA and MMC) evaluated the quality of websites using the DISCERN questionnaire [40] and the JAMA benchmark criteria [41]. The DISCERN questionnaire is commonly applied to assess the quality of written information on health treatment choices. The instrument is divided into the following 3 sections: (1) reliability of the publication, (2) specific details of the information about treatment choices, and (3) overall quality rating of the document. It consists of 16 questions with 5-level Likert scale, where the score " 1 " indicates that the criterion was not fulfilled and the score " 5 " indicates that the criterion was completely satisfied. The total DISCERN score varies between 15 and 80, as the second question must be disregarded when the first question is scored " 1 ." Typically, only the results of the first and second sections of this instrument are used to qualify the health content of documents, as follows: very poor (15-26), poor (27-38), fair (39-50), good (51-62), and excellent (63-75) [47].

The JAMA benchmark consists of a series of 4 qualitative criteria that refer to the description of the authorship (author's name, affiliations, and credentials), attribution (effective references of content), currency (presence of dates of posts and updates of information), and disclosure (the statement of any potential conflicts of interest) of websites. For each fulfilled criterion, 1 point is given, with a total score of 0 to 4 .

The websites that were divergently qualified by the examiners were reassessed to the achievement of a consensus score.

\section{Readability Measures}

The FRE-BP [40] was used to assess the readability of the websites based on the following formula: FRE-BP=248.835-(84.6×syllables per word $)-(1.015 \times$ words per sentence). These metrics were calculated using the online tool Readable.io (Readable.io, Bolney, England) [48] through the information of the respective Uniform Resource Locator (URL) of each website. All analyses were performed based on the overall written content downloaded from these links. The reading difficulty of a text is presented according to the following scores: very easy (75-100), easy (50-75), difficult (25-50), and very difficult (0-25).

\section{Statistical Analysis}

Data were analyzed with the Statistical Package for Social Science (version 21.0; SPSS, Chicago, USA). Although the hypothesis of normal distribution of data was not confirmed by the Kolmogorov-Smirnov test, the statistical analysis was performed by the application of nonparametric tests. The internal consistency of DISCERN was determined by Cronbach alpha. The interrater reliability of DISCERN and JAMA scores provided by the independent examiners was assessed by intraclass correlation coefficient (ICC) for the absolute concordance. The correlations between distinct measures were demonstrated by the Spearman rank correlation coefficients. The significant differences between the dichotomized natures of websites were observed by Mann-Whitney U test. The clusters that emerged from the similarity of websites' identities were determined by the hierarchical clustering analysis using the Ward minimum variance method. Distinct clusters were compared by Kruskal-Wallis test and post hoc Dunn test. $P$ values of $<.05$ were considered significant for all analyses.

\section{Results}

\section{Websites}

A total of 188 websites were obtained through the first links sequentially retrieved from Google Search $(\mathrm{n}=120)$, Baidu $(\mathrm{n}=25)$, Yahoo! $(\mathrm{n}=23)$, and Bing $(\mathrm{n}=20)$. Duplicates $(\mathrm{n}=63)$, nonspecific websites $(n=21)$, inaccessible links $(n=7)$, and scientific contents $(n=22)$ were excluded. A total of 75 websites met the inclusion criteria for the analysis, as shown in Figure 1. As duplicates were also excluded sequentially, there was a great predominance of Google Search links among those that were effectively evaluated, as follows: Google Search $(\mathrm{n}=66)$, Baidu $(\mathrm{n}=1)$, Yahoo! $(\mathrm{n}=7)$, and Bing $(\mathrm{n}=1)$.

Figure 1. Flowchart depicting the systematic selection of dental caries-related Brazilian websites.

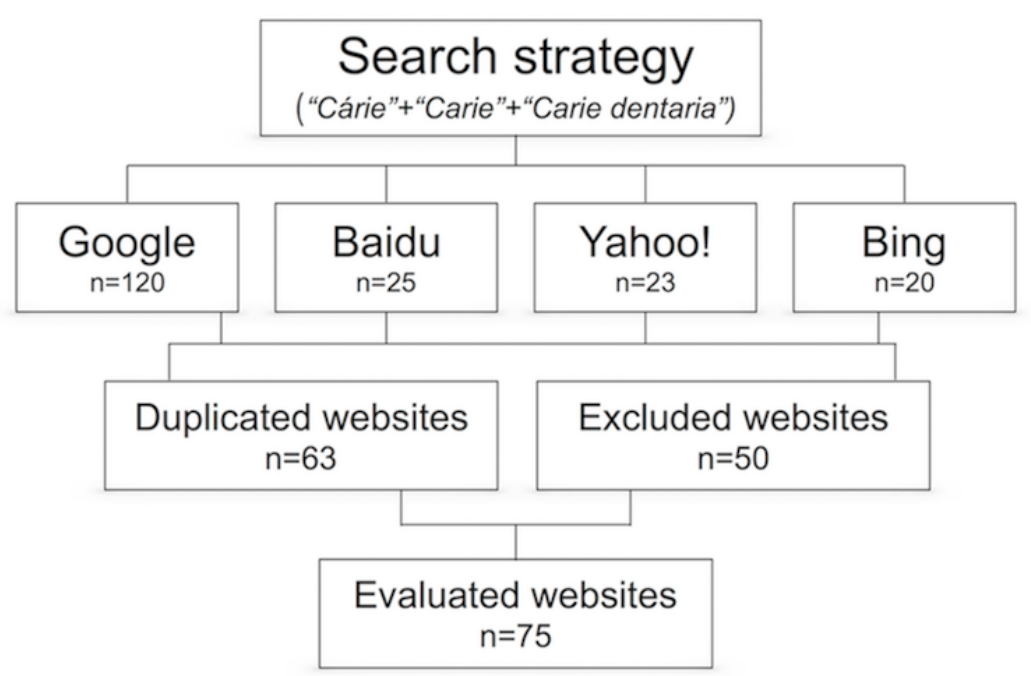




\section{Reliability of Instruments}

The instrument DISCERN displayed an excellent internal consistency (Cronbach alpha=.901), with values of Cronbach alpha varying between .884 and .904 if an item was deleted. A good absolute concordance level was observed between the examiners for the application of the instruments DISCERN questionnaire (ICC $=0.73$, 95\% CI 0.38-0.86) and JAMA benchmark (ICC $=0.72,95 \%$ CI 0.56-0.82).

\section{DISCERN, JAMA, and FRE-BP Scores}

The DISCERN and JAMA scores for each website are depicted in the Multimedia Appendix 2. The contents of the websites were classified as of poor quality in accordance with both scores (Table 1$)$, which were significantly correlated $(\rho=.58, P<.001)$ (Table 2). In addition, the sum of partial DISCERN scores (sections 1 and 2) was strongly correlated with the scores of section $3(\rho=.92, P<.001)$. A total of 20 websites scored $\geq 39$, with a mean overall quality of 3.71. A digital encyclopedia opened to public contributors ("Wikipedia") and a page specialized in dental health information ("ident") showed the two highest DISCERN scores (>60). Only 9\% (7/75) of the websites presented at least three required information displayed by JAMA benchmark criteria. The minor percentage of pages presented authorship $(36 \%, 27 / 75)$, attribution $(18.7 \%, 14 / 75)$, currency $(17.3 \%, 13 / 75)$, and disclosure $(40 \%, 30 / 75)$.
According to the FRE-BP scores, the websites were considered simple and accessible for most population (Table 1). In addition, the difficulty level in reading of websites was weakly and negatively correlated with DISCERN scores (Table 2). The ranking of the websites in the 4 engines was not correlated with DISCERN and FRE-BP scores. Distinctly, JAMA benchmark scores showed a weakly negative correlation with the ranking of the websites retrieved from Google Search (Table 2).

The scores of websites with health- and nonhealth-related authors were statistically similar, considering DISCERN $(P=.29)$ and JAMA benchmark $(P=.47)$ (Table 3$)$. Nevertheless, the written documents produced by health-related authors were considered significantly more difficult than their counterparts.

\section{Websites' Identities}

The hierarchical clustering analysis yielded three distinct websites' identities, as shown in Figure 2. Overall, websites containing contents of all 3 categories (cluster 1) showed higher quality scores than websites containing contents of only 1 (cluster 3 ) or 2 (cluster 2) categories. The DISCERN scores of cluster 1 were statistically higher than those of cluster $3(P=.009)$ (Table 4). Additionally, the percentages of websites with health-related authors were $40.9 \%$ for cluster $1,61.5 \%$ for cluster 2 , and $48.1 \%$ for cluster 3 .

Table 1. Descriptive statistics of scores of DISCERN, the Journal of American Medical Association benchmark, and Flesch Reading Ease adapted to Brazilian Portuguese.

\begin{tabular}{|c|c|c|c|c|c|c|}
\hline Outcomes & $S 1^{\mathrm{a}}$ & $\mathrm{S} 2^{\mathrm{a}}$ & $\mathrm{S}^{\mathrm{a}}$ & $\begin{array}{l}\text { DISCERN } \\
(\mathrm{S} 1+\mathrm{S} 2)\end{array}$ & $\mathrm{JAMA}^{\mathrm{b}}$ & FRE-BP ${ }^{c}$ \\
\hline Mean (SD) & $18.89(5.70)$ & $14.59(5.40)$ & $2.20(0.85)$ & $33.48(9.06)$ & $1.12(0.97)$ & $62.93(10.15)$ \\
\hline Median & 18.00 & 14.00 & 2.00 & 33.00 & 1.00 & 63.56 \\
\hline Minimum & 8.00 & 7.00 & 1.00 & 18.00 & 0.00 & 37.98 \\
\hline Maximum & 34.00 & 28.00 & 4.00 & 60.00 & 3.00 & 88.23 \\
\hline
\end{tabular}

${ }^{\mathrm{a}} \mathrm{S} 1, \mathrm{~S} 2$, and S3: 3 different sections of DISCERN.

bJAMA: the Journal of American Medical Association.

${ }^{\mathrm{c}}$ FRE-BP: Flesch Reading Ease adapted to Brazilian Portuguese.

Table 2. Cross correlation between the ranking of websites presented in the 4 engines, DISCERN, the Journal of American Medical Association benchmark, and Flesch Reading Ease adapted to Brazilian Portuguese.

\begin{tabular}{lllllll}
\hline Outcomes & $\begin{array}{l}\text { Ranking Baidu } \\
(\rho, P)\end{array}$ & $\begin{array}{l}\text { Ranking Yahoo! } \\
(\rho, P)\end{array}$ & $\begin{array}{l}\text { Ranking Bing } \\
(\rho, P)\end{array}$ & $\begin{array}{l}\text { DISCERN } \\
\left(\mathrm{S} 1+\mathrm{S} 2^{\mathrm{a}} ; \rho, P\right)\end{array}$ & $\begin{array}{l}\mathrm{JAMA}^{\mathrm{b}} \\
(\rho, P)\end{array}$ & $\begin{array}{l}\text { FRE-BP }^{\mathrm{c}} \\
(\rho, P)\end{array}$ \\
\hline Ranking Google & .78 .02 & $.86<.001$ & $.78, .02$ & $-.22, .08$ & $-.28, .02$ & $.03, .84$ \\
Ranking Baidu & & $.60, .40$ & $.95,<.001$ & $-.19, .53$ & $-. .11, .73$ & $.02, .96$ \\
Ranking Yahoo! & & $.77, .07$ & $.22, .39$ & $-.02, .93$ & $-.04, .89$ \\
Ranking Bing & & & $-.36, .23$ & $-.19, .54$ & $.03, .92$ \\
DISCERN & & & & $.58,<.001$ & $-.23, .05$ \\
JAMA & & & & & & \\
\hline
\end{tabular}

${ }^{\mathrm{a}} \mathrm{S} 1+\mathrm{S} 2=$ sum of scores of sections 1 and 2 of DISCERN

bJAMA: the Journal of American Medical Association.

${ }^{\mathrm{c}}$ FRE-BP: Flesch Reading Ease adapted to Brazilian Portuguese. 
Table 3. Descriptive statistics of websites with health- and nonhealth-related authors for DISCERN, the Journal of American Medical Association benchmark, and Flesch Reading Ease adapted to Brazilian Portuguese.

\begin{tabular}{|c|c|c|c|c|c|c|}
\hline Websites & $S 1^{\mathrm{a}}$ & $\mathrm{S}^{\mathrm{a}}$ & $\mathrm{S}^{\mathrm{a}}$ & $\begin{array}{l}\text { DISCERN } \\
(\mathrm{S} 1+\mathrm{S} 2)\end{array}$ & $\mathrm{JAMA}^{\mathrm{b}}$ & FRE-BP ${ }^{c}$ \\
\hline \multicolumn{7}{|c|}{ Health-related authors $(\mathbf{n}=38)$} \\
\hline $\operatorname{Mean}(\mathrm{SD})^{\mathrm{d}, \mathrm{e}}$ & $19.58(5.76)$ & $14.68(5.02)$ & $2.34(0.82)$ & $34.26(8.85)$ & $1.05(1.01)$ & $63.26(10.15)$ \\
\hline Median & 18.00 & 14.00 & 2.00 & 33.00 & 1.00 & 63.87 \\
\hline Minimum & 11.00 & 7.00 & 1.00 & 18.00 & 0.00 & 37.98 \\
\hline Maximum & 34.00 & 26.00 & 4.00 & 58.00 & 3.00 & 88.23 \\
\hline \multicolumn{7}{|c|}{ Nonhealth-related authors $(n=37)$} \\
\hline $\operatorname{Mean}(\mathrm{SD})^{\mathrm{d}, \mathrm{e}}$ & $18.19(5.76)$ & $14.49(5.75)$ & $2.05(0.88)$ & $32.68(9.33)$ & $1.19(0.94)$ & $59.75(10.34)$ \\
\hline Median & 18.00 & 15.00 & 2.00 & 33.00 & 1.00 & 62.55 \\
\hline Minimum & 8.00 & 7.00 & 1.00 & 18.00 & 0.00 & 46.24 \\
\hline Maximum & 33.00 & 28.00 & 4.00 & 60.00 & 3.00 & 72.73 \\
\hline
\end{tabular}

${ }^{\mathrm{a}} \mathrm{S} 1, \mathrm{~S} 2$, and S3: 3 different sections of DISCERN.

bJAMA: the Journal of American Medical Association.

${ }^{c}$ FRE-BP: Flesch Reading Ease adapted to Brazilian Portuguese.

${ }^{\mathrm{d}, \mathrm{e}}$ Significant statistical differences between the groups (Mann-Whitney $U$ test, $P<.05$ ). 
Figure 2. Cluster analysis of the websites. (A) The representation of websites' IDs regarding the content of information: etiology (1), treatment (2), and/or prevention (3) of dental caries. Red and black bars mean the presence and absence of the type of information, respectively. (B) Dendrogram depicts three clusters originated from the websites' IDs (hierarchical clustering analysis by Ward's minimum variance method).

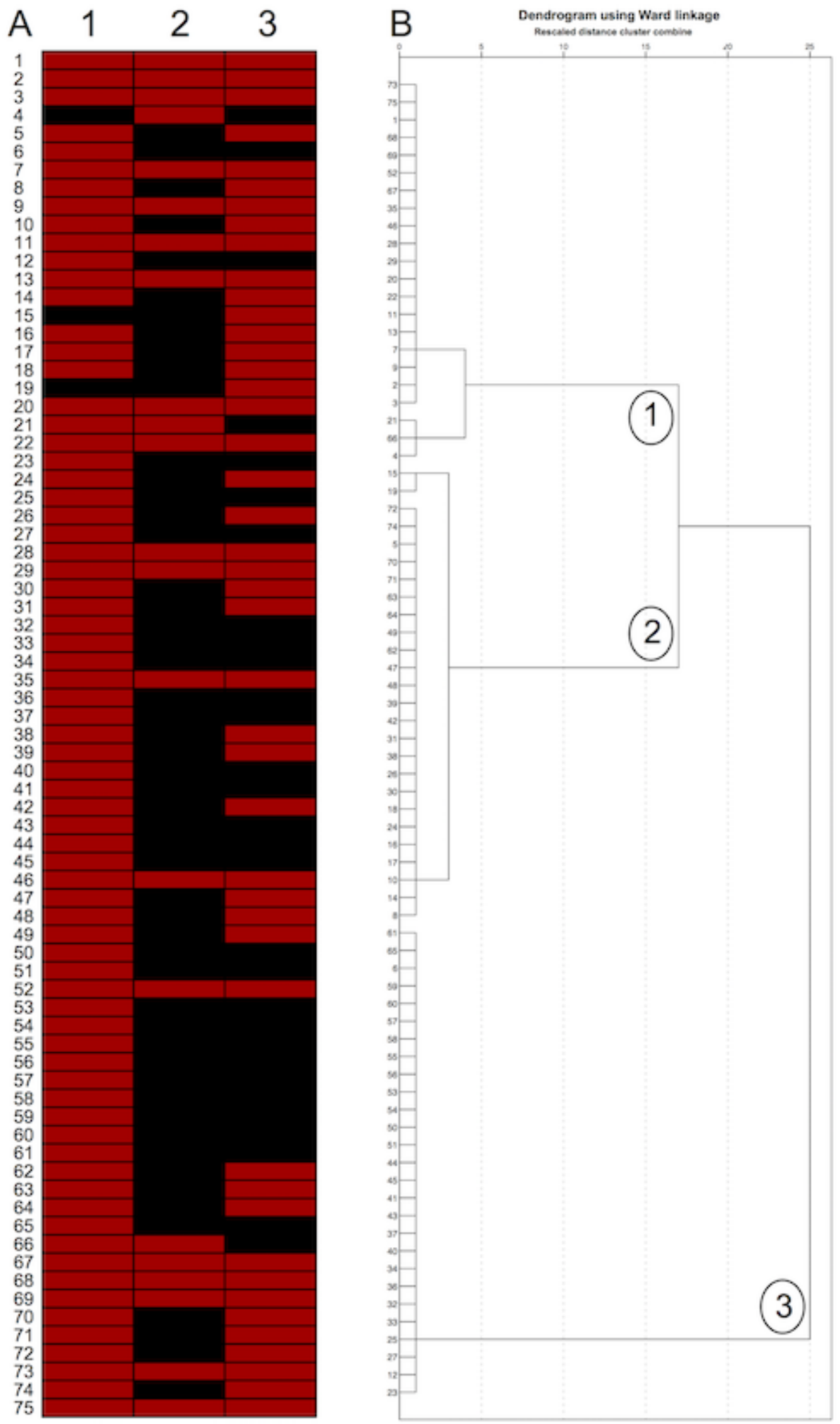


Table 4. Descriptive statistics of different clusters of websites for DISCERN, the Journal of American Medical Association benchmark, and Flesch Reading Ease adapted to Brazilian Portuguese.

\begin{tabular}{|c|c|c|c|c|c|c|}
\hline Cluster & $\mathrm{S} 1^{\mathrm{a}}$ & $\mathrm{S} 2^{\mathrm{a}}$ & $\mathrm{S}^{\mathrm{a}}$ & DISCERN & $\mathrm{JAMA}^{\mathrm{b}}$ & FRE-BP ${ }^{c}$ \\
\hline \multicolumn{7}{|l|}{$1(n=22)$} \\
\hline Mean $(\mathrm{SD})^{\mathrm{d}, \mathrm{e}, \mathrm{f}}$ & $19.05(5.64)$ & $18.05(6.26)$ & $2.41(1.01)$ & $39.50(11.41)$ & $1.05(1.00)$ & $60.04(10.87)$ \\
\hline Median & 18.50 & 17.50 & 2.50 & 38.50 & 1.00 & 57.03 \\
\hline Minimum & 8.00 & 9.00 & 1.00 & 22.00 & 0.00 & 41.23 \\
\hline Maximum & 32.00 & 28.00 & 4.00 & 64.00 & 3.00 & 78.86 \\
\hline \multicolumn{7}{|l|}{$2(n=26)$} \\
\hline Mean $(\mathrm{SD})^{\mathrm{d}, \mathrm{e}, \mathrm{f}}$ & $18.85(4.65)$ & $15.50(3.78)$ & $2.35(0.75)$ & $36.69(8.19)$ & $1.19(0.85)$ & $65.61(7.80)$ \\
\hline Median & 18.00 & 16.00 & 2.00 & 35.00 & 1.00 & 66.03 \\
\hline Minimum & 12.00 & 8.00 & 1.00 & 22.00 & 0.00 & 48.57 \\
\hline Maximum & 34.00 & 24.00 & 4.00 & 62.00 & 3.00 & 80.28 \\
\hline \multicolumn{7}{|l|}{$3(n=27)$} \\
\hline Mean & $18.81^{\mathrm{d}}$ & $10.89^{\mathrm{e}}$ & $1.89^{\mathrm{d}}$ & $31.59^{\mathrm{f}}$ & $1.11^{\mathrm{d}}$ & $62.69^{d}$ \\
\hline $\mathrm{SD}^{\mathrm{g}}$ & 6.82 & 3.33 & 0.75 & 8.69 & 1.09 & 11.15 \\
\hline Median & 16.00 & 11.00 & 2.00 & 29.00 & 1.00 & 63.06 \\
\hline Minimum & 11.00 & 7.00 & 1.00 & 19.00 & 0.00 & 37.98 \\
\hline Maximum & 33.00 & 19.00 & 3.00 & 47.00 & 3.00 & 88.23 \\
\hline
\end{tabular}

${ }^{\mathrm{a}} \mathrm{S} 1, \mathrm{~S} 2$, and S3: 3 different sections of DISCERN.

bJAMA: the Journal of American Medical Association.

${ }^{c}$ FRE-BP: Flesch Reading Ease adapted to Brazilian Portuguese.

d,e,f Significant statistical differences between the groups (Kruskal-Wallis test and post hoc Dunn test, $P<.05$ ).

\section{Discussion}

\section{Principal Findings}

To the best of our knowledge, this is the first study to assess the quality of dental caries-related information on Brazilian websites. In general, our results showed a predominance of low-quality contents, with a low rate of websites $(26.7 \%)$ being classified as acceptable to high-quality levels (DISCERN $\geq 39$ ). These results are consistent with the results of similar studies [49,50]; Blizniuk et al [49] demonstrated lack of quality of dental caries-related information on English websites (DISCERN=44), whereas Leite and Correia [50] identified only 4 out of 75 Portuguese dental caries-related websites certified with the Health On the Net Foundation (HON) code, a trustworthy certification granted by a nongovernmental institution that evaluates the quality of health information on the Internet [51]. However, we did not consider the HON code in our methods, as only 1 Brazilian website was certified. Surprisingly, the content of this website was qualified as inadequate by both instruments utilized in this study.

We believe that the assessment of the quality of websites was improved by the simultaneous application of distinct criteria, particularly because they were only fairly correlated. Additionally, the outstanding internal consistency and interrater agreement of DISCERN when employed in these analyses are noteworthy. In contrast, the determination of the internal

consistency of the JAMA benchmark is limited because it aims at the elucidation of specific data about technical and editorial production of websites. Although its four elements should be better interpreted individually, we calculated the central tendency measures of the JAMA benchmark to evaluate its relationship with other indicators.

The strict investigation executed by 2 health professionals may be linked to perception biases through the underestimation of the quality of websites; nevertheless, Griffiths and Christensen [52] revealed no significant differences between the scores of DISCERN given by professionals and laypersons. In addition, as cluster-based results were not influenced by the nature of websites' authorship, the better performance of websites that published topics about etiology, prevention, and treatment of dental caries reflects the significant impact of the completeness of contents on the process of qualification of information. This finding is supported by the study of Diviani et al [29], who showed that the amount of information available on a website influences the perception of improved quality of digital contents by Internet users. No significant differences were found when comparing DISCERN scores with JAMA scores of websites of health- and nonhealth-related authors, suggesting that the quality criteria considered in these instruments were not a concern for the most dentists and/or dental companies during the production of electronic contents.

Although the negative correlation between FRE-BP and DISCERN scores was discrete, this trend should be regarded 
as an exacerbating factor for the impact of the low quality of information on the Internet users, as it demonstrates that more accessible contents are even worse in quality. This fact raises an important concern with regard to the high percentage of basic literate Brazilian youths (99\%) and adults (93\%) [53], as the understanding of medical information probably requires more advanced educational abilities [28]. In this context, the shared decision-making process could be deteriorated by the misunderstanding of health information and the development of harmful health beliefs.

\section{Design considerations}

According to the Vital Signs report [54], there are 4 types of individuals with regard to health care situation: (1) those who agree and accept the treatment decision, (2) those who access the Web to confirm the diagnosis given by a professional, (3) those who are involved in the decision-making process, and (4) those who are in complete control of their treatment relying on the information found by themselves. In this context, although health professionals are still considered the most important source of health advice, the easier and more affordable access to the Internet predisposes people to seek health counseling online [29]. Furthermore, 65\% of health seekers frequently begin their searches using an engine bar instead of looking for information on specific portals [54]. Consequently, millions of health-related queries are entered in Google Search daily [55]; therefore, the methodological approach adopted for the construction of our search strategy probably improved the chances of retrieving the websites in a similar way to that usually performed by netizens.

To evaluate the correlation of the order of appearance of links in the search engines with the quality of their contents, we assessed a quite larger number of websites than the Internet users could be interested in [56]. For instance, Google's PageRank uses more than 200 factors based on Larry Page's algorithms to order the links by their relevance from the query [57]. In this study, the links found on the Google's first page were represented by 5 blogs, 2 dental clinics, and 1 commercial website. Their contents were alarming, for example, with the description of dental treatments without dentists. In addition, the order of appearance of the websites was not correlated with DISCERN scores in the 4 different engines, that is, the algorithms created to retrieve the links associated with dental caries seemed to not have any relationship with the quality of available information, which may contribute even more with the deterioration of the health education process.

\section{Limitations}

This study presents some limitations. First, although laypersons could be interested in reading more specialized documents, the links associated to scientific publications, such as papers and books, were not considered into our analyses. This decision was based on two main reasons: (1) the DISCERN was developed to assess the quality of information presented to health seekers, that is, its application would be inadequate and unproductive to analyze scientific contents; and (2) probably, the great specificity and the technical language of scientific papers lead people to look for documents that explore more general knowledge about the disease. Second, it was not feasible to evaluate other types of website media, such as figures, films, and podcasts, as the DISCERN was specifically developed to assess the quality of written documents. Finally, the unknown audience of the websites prevented the determination of the impact of each source on the diffusion of dental knowledge, although our results were supposedly obtained from the most accessed websites, considering that they were the first dental caries-related links retrieved by search engines.

\section{Challenges}

The development of specific regulations in this field is arduous, requiring an intense debate to avoid the suppression of the rights of freedom of expression and opinion [58]. Likewise, it is almost impossible to control the publication of Web contents, particularly because of the diffusion of personal opinion contained in health blogs. The use of codes and seals for the certification of websites could be a good approach to indicate the useful health information, particularly if the accreditation is based on rigorous criteria and if the Internet users can easily view the certification on the website. Nevertheless, the continuous consumption of misleading knowledge could deteriorate the person-dentist relationship; hence, the professional should be prepared to face this challenge effectively, advising and encouraging their patients to explore information on recommended websites, warning people about the risks of health home practices, and contributing to the production of good quality electronic materials.

\section{Conclusions}

In conclusion, regarding the present sample of Brazilian websites, dental caries-related contents were considered simple, accessible, and of poor quality based on the results of FRE-BP, DISCERN, and JAMA benchmark scores, respectively. This pattern does not seem to rely on the natures of websites' authorship but on the multiplicity of categories of information that they covered. These findings indicate the need for the development of special policies focused on the stimulus for the production and publication of Web health information, encouraging dentists to guide their patients to search for recommended oral health websites.

\section{Acknowledgments}

This research was supported by the Conselho Nacional de Desenvolvimento Científico e Tecnológico (CNPq), grant \#134226/2015-1.

\section{Conflicts of Interest}

None declared. 


\section{Multimedia Appendix 1}

List of 56 dental caries-related keywords retrieved in Google Search and Keyword Planner (written in Brazilian Portuguese). [PDF File (Adobe PDF File), 29KB-Multimedia Appendix 1]

\section{Multimedia Appendix 2}

List of websites and respective identities, ranking, DISCERN, and JAMA benchmark scores.

[PDF File (Adobe PDF File), 31KB-Multimedia Appendix 2]

\section{References}

1. Bragazzi NL. From P0 to P6 medicine, a model of highly participatory, narrative, interactive, and "augmented" medicine: some considerations on Salvatore Iaconesi's clinical story. Patient Prefer Adherence 2013;7:353-359 [FREE Full text] [doi: 10.2147/PPA.S38578] [Medline: 23650443]

2. World Health Organization. WHO. Health Promotion URL: http://www.who.int/topics/health promotion/en/[WebCite Cache ID 6oGmU6nrm]

3. Fahy E, Hardikar R, Fox A, Mackay S. Quality of patient health information on the Internet: reviewing a complex and evolving landscape. Australas Med J 2014;7(1):24-28 [FREE Full text] [doi: 10.4066/AMJ.2014.1900] [Medline: 24567763]

4. Cotten SR, Gupta SS. Characteristics of online and offline health information seekers and factors that discriminate between them. Soc Sci Med 2004 Nov;59(9):1795-1806. [doi: 10.1016/j.socscimed.2004.02.020] [Medline: 15312915]

5. Salmon P, Hall GM. Patient empowerment or the emperor's new clothes. J R Soc Med 2004 Feb;97(2):53-56 [FREE Full

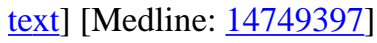

6. Nutbeam D. Health promotion glossary. Health Promot 1986 May;1(1):113-127. [Medline: $\underline{10318625]}$

7. Lee K, Hoti K, Hughes JD, Emmerton LM. Consumer use of "Dr Google": a survey on health information-seeking behaviors and navigational needs. J Med Internet Res 2015;17(12):e288 [FREE Full text] [doi: 10.2196/jmir.4345] [Medline: 26715363]

8. McCloud RF, Okechukwu CA, Sorensen G, Viswanath K. Beyond access: barriers to internet health information seeking among the urban poor. J Am Med Inform Assoc 2016 May 20;23(6):1053-1059. [doi: 10.1093/jamia/ocv204] [Medline: 27206459]

9. Pluye P, Grad R, Repchinsky C, Jovaisas B, Johnson-Lafleur J, Carrier M, et al. Four levels of outcomes of information-seeking: a mixed methods study in primary health care. J Am Soc Inf Sci Tec 2012 Dec 10;64(1):108-125. [doi: 10.1002/asi.22793]

10. Barry MJ, Edgman-Levitan S. Shared decision making--pinnacle of patient-centered care. N Engl J Med 2012 Mar 01;366(9):780-781. [doi: 10.1056/NEJMp1109283] [Medline: 22375967]

11. Hanna A. OMA. 2010. Patient-Centred Care URL: https://www.oma.org/wp-content/uploads/patient-centredcare.pdf [accessed 2017-12-11] [WebCite Cache ID 6vcoCSNoG]

12. Marcenes W, Kassebaum NJ, Bernabé E, Flaxman A, Naghavi M, Lopez A, et al. Global burden of oral conditions in 1990-2010: a systematic analysis. J Dent Res 2013 Jul;92(7):592-597 [FREE Full text] [doi: 10.1177/0022034513490168] [Medline: 23720570]

13. World Dental Federation. fdiworldental. 2015. The Challenge of Oral Disease - a call for global action URL: http://www. fdiworldental.org/publications/oral-health-atlas/oral-health-atlas-(2015).aspx[WebCite Cache ID 6oV3GslLe]

14. Kassebaum NJ, Bernabé E, Dahiya M, Bhandari B, Murray CJ, Marcenes W. Global burden of untreated caries: a systematic review and metaregression. J Dent Res 2015 May;94(5):650-658. [doi: 10.1177/0022034515573272] [Medline: 25740856]

15. Moreira RS. cdn.intechopen. 2012. Epidemiology of dental caries in the world URL: http://cdn.intechopen.com/pdfs/29340. pdf [WebCite Cache ID 6oV5QorDs]

16. Bourgeois DM, Llodra JC. Global burden of dental condition among children in nine countries participating in an international oral health promotion programme, 2012-2013. Int Dent J 2014 Oct;64(Suppl 2):27-34. [doi: 10.1111/idj.12129] [Medline: 25209648]

17. Ramos-Jorge J, Pordeus IA, Ramos-Jorge ML, Marques LS, Paiva SM. Impact of untreated dental caries on quality of life of preschool children: different stages and activity. Community Dent Oral Epidemiol 2014 Aug;42(4):311-322. [doi: 10.1111/cdoe.12086] [Medline: 24266653]

18. de Pinho AM, Campos AC, Ferreira EF, Vargas AM. Toothaches in the daily lives of Brazilian adults. Int J Environ Res Public Health 2012 Aug;9(8):2587-2600 [FREE Full text] [doi: 10.3390/ijerph9082587] [Medline: 23066384]

19. Haikal DS, Martins AM, Aguiar PH, Silveira MF, de Paula AM, Ferreira EF. [Access to information on oral hygiene and tooth loss due to caries among adults]. Cien Saude Colet 2014 Jan;19(1):287-300 [FREE Full text] [doi:

10.1590/1413-81232014191.2087] [Medline: 24473625]

20. Petersen PE. The World Oral Health Report 2003: continuous improvement of oral health in the 21st century--the approach of the WHO Global Oral Health Programme. Community Dent Oral Epidemiol 2003 Dec;31(Suppl 1):3-23. [Medline: $\underline{15015736]}$ 
21. Aguirre PEA, Coelho MM, Oliveira TM, Rios D, Cruvinel AFP, Cruvinel T. What Google could inform us about the people's interests on dental caries in different populations? Caries Res. In print.

22. Cummins D. The impact of research and development on the prevention of oral diseases in children and adolescents: an industry perspective. Pediatr Dent 2006;28(2):118-27; discussion 192. [Medline: 16708786]

23. Featherstone J. The caries balance: contributing factors and early detection. J Calif Dent Assoc 2003 Feb;31(2):129-133. [Medline: 12636316]

24. Marsh PD. Dental plaque as a biofilm and a microbial community - implications for health and disease. BMC Oral Health 2006 Jun 15;6(Suppl 1):S14 [FREE Full text] [doi: 10.1186/1472-6831-6-S1-S14] [Medline: 16934115]

25. Michie S, Rosebert C, Heaversedge J, Madden S, Parbhoo S. The effects of different kinds of information on women attending an out-patient breast clinic. Psychol Health Med 1996 Oct;1(3):285-296. [doi: 10.1080/13548509608402225]

26. Mead N, Varnam R, Rogers A, Roland M. What predicts patients' interest in the Internet as a health resource in primary care in England? J Health Serv Res Policy 2003 Jan;8(1):33-39. [doi: 10.1258/13558190360468209] [Medline: 12683432]

27. Breckons M, Jones R, Morris J, Richardson J. What do evaluation instruments tell us about the quality of complementary medicine information on the internet? J Med Internet Res 2008;10(1):e3 [FREE Full text] [doi: 10.2196/jmir.961] [Medline: 18244894]

28. Sillence E, Briggs P, Harris PR, Fishwick L. How do patients evaluate and make use of online health information? Soc Sci Med 2007 May;64(9):1853-1862. [doi: 10.1016/j.socscimed.2007.01.012] [Medline: 17328998]

29. Diviani N, van den Putte B, Meppelink CS, van Weert J. Exploring the role of health literacy in the evaluation of online health information: insights from a mixed-methods study. Patient Educ Couns 2016 Jun;99(6):1017-1025. [doi: 10.1016/j.pec.2016.01.007] [Medline: 26817407]

30. Del Giglio A, Abdala B, Ogawa C, Amado D, Carter D, Gomieiro F, et al. Quality of internet information available to patients on websites in Portuguese. Rev Assoc Med Bras (1992) 2012;58(6):645-649 [FREE Full text] [Medline: 23250091]

31. Robins S, Barr HJ, Idelson R, Lambert S, Zelkowitz P. Online health information regarding male infertility: an evaluation of readability, suitability, and quality. Interact J Med Res 2016 Oct 21;5(4):e25 [FREE Full text] [doi: 10.2196/ijmr.6440] [Medline: 27769954]

32. Saeed F, Anderson I. Evaluating the quality and readability of Internet information on meningiomas. World Neurosurg 2017 Jan;97:312-316. [doi: 10.1016/j.wneu.2016.10.001] [Medline: 27742505]

33. Irwin JY, Thyvalikakath T, Spallek H, Wali T, Kerr AR, Schleyer T. English and Spanish oral cancer information on the internet: a pilot surface quality and content evaluation of oral cancer web sites. J Public Health Dent 2011;71(2):106-116 [FREE Full text] [Medline: 21774133]

34. Weymann N, Härter M, Dirmaier J. Quality of online information on type 2 diabetes: a cross-sectional study. Health Promot Int 2015 Dec;30(4):821-831. [doi: 10.1093/heapro/dau019] [Medline: 24688114]

35. Livas C, Delli K, Ren Y. Quality evaluation of the available Internet information regarding pain during orthodontic treatment. Angle Orthod 2013 May;83(3):500-506. [doi: 10.2319/052512-435.1] [Medline: 23025687]

36. López-Jornet P, Camacho-Alonso F. The quality of patient-orientated Internet information on oral lichen planus: a pilot study. J Eval Clin Pract 2010 Oct;16(5):883-886. [doi: 10.1111/j.1365-2753.2009.01206.x] [Medline: 20586847]

37. Bruce-Brand RA, Baker JF, Byrne DP, Hogan NA, McCarthy T. Assessment of the quality and content of information on anterior cruciate ligament reconstruction on the internet. Arthroscopy 2013 Jun;29(6):1095-1100. [doi: 10.1016/j.arthro.2013.02.007] [Medline: 23582738]

38. Kaicker J, Dang W, Mondal T. Assessing the quality and reliability of health information on ERCP using the DISCERN instrument. Health Care: Current Reviews 2016;4(2):104. [doi: 10.4172/hccr.1000104]

39. McGoldrick DM, Kielty P, Cotter C. Quality of information about maxillofacial trauma on the Internet. Br J Oral Maxillofac Surg 2017 Feb;55(2):141-144. [doi: 10.1016/j.bjoms.2016.09.020] [Medline: 28029446]

40. Discern. The DISCERN Instrument URL: http://www.discern.org.uk/discern instrument.php [accessed 2017-02-15] [WebCite Cache ID 6oIqjinx6I]

41. Silberg WM, Lundberg GD, Musacchio RA. Assessing, controlling, and assuring the quality of medical information on the Internet: Caveant lector et viewor--Let the reader and viewer beware. J Am Med Assoc 1997 Apr 16;277(15):1244-1245. [Medline: 9103351$]$

42. Martins T, Ghiraldelo C, Nunes M, Oliveira JO. Readability formulas applied to textbooks in Brazilian Portuguese. São Carlos: Instituto de Ciências Matemáticas de São Carlos; 1996:1-14.

43. Net Market Share. netmarketshare. 2017. Desktop Search Engine Market Share URL: https://www.netmarketshare.com/ search-engine-market-share.aspx?qprid=4\&qpcustomd=0[WebCite Cache ID 6oInF2BWx]

44. Webcitation. What is WebCite®? URL: http://www.webcitation.org/index [accessed 2017-12-11] [WebCite Cache ID 6vcpCuke8]

45. Nassiri M, Mohamed O, Berzins A, Aljabi Y, Mahmood T, Chenouri S, et al. Surfing behind a boat: quality and reliability of online resources on scaphoid fractures. J Hand Surg Asian Pac Vol 2016 Oct;21(3):374-381. [doi:

10.1142/S2424835516500375] [Medline: 27595957]

46. Sturn A, Quackenbush J, Trajanoski Z. Genesis: cluster analysis of microarray data. Bioinformatics 2002 Jan;18(1):207-208. [Medline: 11836235] 
47. Hargrave DR, Hargrave UA, Bouffet E. Quality of health information on the Internet in pediatric neuro-oncology. Neuro Oncol 2006 Apr;8(2):175-182 [FREE Full text] [doi: 10.1215/15228517-2005-008] [Medline: 16533758]

48. Readable.io. readable. Readibility Score URL: https://readable.io/[WebCite Cache ID 6mLDb9ZEq]

49. Blizniuk A, Furukawa S, Ueno M, Kawaguchi Y. Evaluation of English websites on dental caries by using consumer evaluation tools. Oral Health Prev Dent 2016;14(4):363-369. [doi: 10.3290/j.ohpd.a35746] [Medline: 26973989]

50. Leite F, Correia A. Quality evaluation of websites with information on childhood dental caries in Portuguese language. Rev Odonto Cienc 2011;26(2):116-120. [doi: 10.1590/S1980-65232011000200004]

51. Health On the Net Foundation. hon.ch. HON Code URL: http://www.hon.ch/HONcode/Patients/Visitor/visitor.html[WebCite Cache ID 6oV4UTKT4]

52. Griffiths KM, Christensen H. Website quality indicators for consumers. J Med Internet Res 2005 Nov 15;7(5):e55 [FREE Full text] [doi: 10.2196/jmir.7.5.e55] [Medline: 16403719]

53. World Bank Data. data.worldbank. 2017. Brasil: Basic Literacy URL: http://data.worldbank.org/indicator/SE.ADT.LITR. ZS?end=2015\&locations $=$ BR\&start=2006\&view $=$ chart

54. Taylor H, Leitman R. ehealthstrategies. 2001. The increasing impact of eHealth on consumer behavior URL: http:/ lehealthstrategies.com/files/hi v1 21.pdf [accessed 2017-12-11] [WebCite Cache ID 6vcpX4CUO]

55. Eysenbach G, Kohler C. What is the prevalence of health-related searches on the World Wide Web? Qualitative and quantitative analysis of search engine queries on the internet. AMIA Annu Symp Proc 2003:225-229 [FREE Full text] [Medline: 14728167$]$

56. Eysenbach G, Köhler C. How do consumers search for and appraise health information on the world wide web? Qualitative study using focus groups, usability tests, and in-depth interviews. Br Med J 2002 Mar 9;324(7337):573-577 [FREE Full text] [Medline: $\underline{11884321]}$

57. Page L, Brin S, Motwani R, Winograd T. ilpubs.stanford. 1999. The PageRank citation ranking: bringing order to the web URL: http://ilpubs.stanford.edu:8090/422/1/1999-66.pdf [accessed 2017-02-23] [WebCite Cache ID 6oV66KvwP]

58. Risk A, Dzenowagis J. Review of internet health information quality initiatives. J Med Internet Res 2001;3(4):E28 [FREE Full text] [doi: 10.2196/jmir.3.4.e28] [Medline: 11772543]

\section{Abbreviations \\ FRE-BP: Flesch Reading Ease adapted to Brazilian Portuguese \\ HON: Health On the Net Foundation \\ ICC: interclass correlation coefficient \\ JAMA: the Journal of American Medical Association}

Edited by G Eysenbach; submitted 10.03.17; peer-reviewed by K Lee, S Robins, N Bragazzi; comments to author 12.07.17; revised
version received 25.08.17; accepted 30.10.17; published 13.12.17
Please cite as:
Aguirre PEA, Coelho MM, Rios D, Machado MAAM, Cruvinel AFP, Cruvinel T
Evaluating the Dental Caries-Related Information on Brazilian Websites: Qualitative Study
J Med Internet Res 2017;19(12):e415
URL: http://www.jmir.org/2017/12/e415/
doi: $\underline{10.2196 / \text { jmir.7681 }}$
PMID: $\underline{29237585}$

(CPatricia Estefania Ayala Aguirre, Melina Martins Coelho, Daniela Rios, Maria Aparecida Andrade Moreira Machado, Agnes Fátima Pereira Cruvinel, Thiago Cruvinel. Originally published in the Journal of Medical Internet Research (http://www.jmir.org), 13.12.2017. This is an open-access article distributed under the terms of the Creative Commons Attribution License (https://creativecommons.org/licenses/by/4.0/), which permits unrestricted use, distribution, and reproduction in any medium, provided the original work, first published in the Journal of Medical Internet Research, is properly cited. The complete bibliographic information, a link to the original publication on http://www.jmir.org/, as well as this copyright and license information must be included. 